\title{
Clinical characteristics of italian patients with venous thromboembolism enrolled in the RIETE Registry
}

\section{Caratteristiche cliniche dei pazienti italiani iscritti nel Registro RIETE}

\section{Pierpaolo Di Micco ${ }^{a, *}$, Alessandra Bura-Riviere ${ }^{b}$, Renzo Poggio ${ }^{c}$, Eros Tiraferri $^{d}$, Roberto Quintavalla ${ }^{e}$, Adriana Visonà ${ }^{f}$, Paolo Prandoni ${ }^{g}$, Maurizio Ciammaichella ${ }^{\text {h }}$, Giovanni Barillari ${ }^{i}$, RIETE Investigators ${ }^{1}$}

\author{
${ }^{a}$ Department of Internal Medicine, Ospedale Buonconsiglio Fatebenefratelli, Naples, Italy \\ ${ }^{\mathrm{b}}$ Department of Vascular Medicine, Hôpital de Rangueil, Toulouse, France \\ ' Department of Internal Medicine, Ospedale Galliera, Genova, Italy \\ d Department of Hemostasis and Thrombosis, Ospedale Infermi, Rimini, Italy \\ e Department of Internal Medicine, Azienda Ospedaliera Universitaria, Parma, Italy \\ ${ }^{f}$ Department of Vascular Medicine, Ospedale Castel Franco TV, Castel Franco Veneto, Italy \\ ${ }^{g}$ Department of Medical and Surgical Sciences, Clinica Medical II, University of Padua, Italy \\ ${ }^{\mathrm{h}}$ Department of Emergency and Internal Medicine, Ospedale St. John, Rome, Italy \\ i Department of Internal Medicine, Center for Hemorrhagic and Thrombotic Disorders, Udine, Italy
}

\section{KEYWORDS}

Venous thromboembolism;

RIETE;

Deep vein thrombosis;

Pulmonary embolism;

Surgery;

Immobility.

\section{Summary}

Introduction: The clinical characteristics, treatment strategies and outcome of patients with venous thromboembolism (VTE) may vary from country to country.

Materials and methods: The RIETE (Registro Informatizado su la Enfermedad TromboEmbolica) is an ongoing, prospective registry of consecutive patients with acute, objectively confirmed, symptomatic VTE. Our aim was to assess the influence of surgery and immobility for non-surgical reasons on 3-month outcomes of all Italian patients registered in the RIETE.

Results: Through July 2008, 21,397 patients with acute VTE were registered in the RIETE. Of these, 896 (4.2\%) were Italian, and $360(40 \%)$ presented with pulmonary embolism (PE). Overall, 137 (15\%) developed VTE after surgery; 156 (17\%) developed VTE after $\geq 4$ days of immobility, and $603(67 \%)$ developed VTE in the absence of surgery or immobility. Most patients $(83 \%)$ received initial therapy with low-molecular-weight heparin; $15 \%$ received unfractionated heparin. For long-term therapy, $63 \%$ of patients received vitamin $\mathrm{K}$ antagonists. The incidence of fatal PE

\footnotetext{
* Corresponding author: Department of Internal Medicine, Ospedale Buonconsiglio Fatebenefratelli, via Manzoni 220 - Naples, Italy. E-mail: pdimicco@libero.it (P. Di Micco).

${ }^{1} \mathrm{~A}$ full list of Italian RIETE investigators is provided in the Appendix A.
} 
during the first 3 months of therapy was $1.5 \%$ for patients with postoperative VTE, $7.7 \%$ for who developed VTE after immobility, and $1.2 \%$ for the remaining patients. The incidence of fatal bleeding among these patients was $1.5 \%, 1.9 \%$ and $0.3 \%$, respectively. Of the 137 patients with postoperative VTE, $61 \%$ had received VTE prophylaxis. Of the 156 patients with recent immobility, $24 \%$ had received VTE prophylaxis.

Conclusions: VTE arising after a period of immobility was associated with the highest rates of fatal PE and fatal bleeding during the first 3 months of therapy. The use of thromboprophylaxis in this population should be improved.

(c) 2011 Elsevier Srl. All rights reserved.

\section{Introduction}

A previous Spanish study of patients with acute venous thromboembolism (VTE) showed large differences in outcome (incidence of major bleeding, fatal PE, and fatal bleeding) between surgical patients and immobilized acutely ill medical patients [1]. However, the clinical characteristics, treatment strategies and outcome of patients with VTE may vary from country to country. Until now, these data have not been confirmed in Italian patients. A better knowledge of the influence of the different risk factors on outcome in patients with VTE would be useful to guide new strategies for early diagnosis, prophylaxis and/or therapy.

The RIETE Registry is an ongoing, international (including Spain, France, Italy, Israel, Germany, Republic of Macedonia, Switzerland, and Brazil), multicenter, prospective registry of consecutive patients presenting with symptomatic, acute VTE confirmed by objective tests. It was designed to gather and analyze data about treatment patterns and outcomes in patients with symptomatic, objectively confirmed, acute VTE [2]. Data from this registry have been used to evaluate outcomes after acute VTE, such as the frequency of recurrent VTE, bleeding and mortality, and risk factors for these outcomes $[3,4]$. In this analysis, we assessed the influence of predisposing factors for VTE (i.e., recent surgery or immobility) on the incidence of fatal PE and fatal bleeding during the first 3 months of anticoagulant therapy in all Italian patients enrolled in the registry.

\section{Materials and methods}

\section{Patient Entry Criteria}

Participating hospitals enrolled all patients who meet predefined eligibility criteria. Patients were included if they had symptomatic, acute deep-vein thrombosis (DVT) or pulmonary embolism (PE) confirmed by objective tests (i.e., contrast venography, ultrasonography or impedance plethysmography for suspected DVT; pulmonary angiography, lung scintigraphy or helical computed tomography scan for suspected PE) [5,6]. Patients were excluded if they were participating in a therapeutic clinical trial blinded to medication, or if they would not be available for a 3-month follow-up. All patients provided informed consent for their participation in the study, according to the requirements of each hospital's ethics committee. Data quality was monitored and documented, and a full data audit was performed at periodic intervals.

The RIETE enrolled more than 35,000 patients with VTE between 2001 and February 2011. The registry enrolls patients from several (predominantly European) countries, particularly Spain, Italy and France. We analyzed data from Italy from January 2006 to July 2008. Italy was the first country after Spain to join the registry; it joined in 2006 and had enrolled 896 patients by July 2008.

\section{Study Parameters and Endpoints}

The following parameters were recorded when the qualifying episode of DVT was diagnosed: the patient's sex, age, and body weight; the presence of coexisting conditions, such as chronic heart or lung disease; recent $(<30$ days prior to VTE) major bleeding; the presence of risk factors for DVT, including active cancer (defined as newly diagnosed cancer or cancer that is being treated, i.e., via surgery, chemotherapy, radiotherapy, hormonal, support therapy, or combined treatments), recent immobilization (i.e., nonsurgical patients who were confined to bed with bathroom privileges for $\geq 4$ days in the 2 months prior to VTE diagnosis), surgery (i.e., patients who had undergone an operation in the 2 months prior to VTE); extent of the DVT (distal DVT was DVT confined to the infrapopliteal veins); and laboratory data.

Study endpoints were clinically recognized risk factors, prophylaxis and VTE outcomes (i.e., VTE recurrences, major and minor bleeding complications, and death). Bleeding complications were classified as major or minor according to the criteria established by Doyle et al. Bleeding was classified as "major" if it was overt and led to a transfusion of $2 \mathrm{U}$ of blood or more, if it was fatal, or if it was retroperitoneal or intracranial. Bleeding was defined as minor if it was clinically relevant but did not meet the other criteria for major bleeding.

\section{Use of the RIETE Study Database}

Although it is not intended to influence the routine management of patients participating in the registry, collated data from the RIETE are available on the registry's website (www.riete.org) for use by participating physicians and others in the field. An underlying or coexisting medical condition can be selected from a drop-down list to display data from the RIETE database, including the treatments, 
doses and outcomes of patients with similar clinical profiles. Users can thus compare different therapies and decide which is the most appropriate for their patient, based on previous real-world outcomes.

\section{Data Management and Confidentiality}

$\mathrm{S} \& \mathrm{H}$ Medical Science Service is the coordinating center for the registry and assumes responsibility for all data management activities. Data for each patient are entered on a standard case report form and submitted to the coordinating center via a secure website. Patient, physician and hospital data confidentiality is protected prior to data submission by assigning a unique study number to each patient at enrollment and by deleting or coding all other information that could identify a person or institution. Confidential electronic data are further protected by passwords, and all paper copies of data and reports are stored in a secure facility.

\section{Results}

\section{General data}

Through July 2008, 21,397 patients with acute VTE were enrolled in the RIETE, and 896 (4.2\%) were Italian. Of these Italian patients, 423 (47\%) were males, and mean age was $64 \pm 11$ years. Three hundred sixty patients (40\%) initially presented with PE; 65 (7.3\%) presented with arm DVT, and 351 (39\%) presented with proximal lower-limb DVT. Overall, 156 patients $(17 \%)$ developed the VTE after $\geq 4$ days of immobility, 137 (15\%) after surgery. Two hundred fifty-three patients (28\%) had active cancer, and 337 (38\%) had an unprovoked VTE (Table 1).

\section{Surgery}

One hundred thirty-seven patients suffered VTE after surgical procedures: $47 \%$ of these were males with a mean age of

Table 1 Clinical characteristics and outcomes of Italian patients enrolled in RIETE, according to their risk factors for VTE.

\begin{tabular}{|c|c|c|c|c|}
\hline & All & Surgery & Immobility $\geq 4$ days & Neither \\
\hline Patients, $N$ & 896 & 137 & 156 & 603 \\
\hline \multicolumn{5}{|l|}{ Clinical characteristics } \\
\hline Gender (male) & $423(47 \%)$ & 64 (47\%) & $56(36 \%)$ & $303(50 \%)$ \\
\hline Age (years \pm SD) & $64 \pm 11$ & $60 \pm 20$ & $74 \pm 16$ & $63 \pm 18$ \\
\hline Body weight (kg $\pm S D$ ) & $73 \pm 14$ & $72 \pm 16$ & $71 \pm 12$ & $75 \pm 15$ \\
\hline Height (cm \pm SD) & $167 \pm 11$ & $166 \pm 12$ & $164 \pm 12$ & $167 \pm 11$ \\
\hline Outpatient & $405(46 \%)$ & 46 (34\%) & $46(30 \%)$ & $313(53 \%)$ \\
\hline \multicolumn{5}{|l|}{ Underlying conditions } \\
\hline Chronic lung disease & $59(6.6 \%)$ & $11(8.0 \%)$ & 19 (12\%) & $29(4.8 \%)$ \\
\hline Chronic heart failure & $48(5.4 \%)$ & $4(2.9 \%)$ & $21(14 \%)$ & $23(3.8 \%)$ \\
\hline $\mathrm{CrCl}<30 \mathrm{~mL} / \mathrm{min}$ & $41(4.7 \%)$ & $4(3.0 \%)$ & $13(8.6 \%)$ & $24(4.1 \%)$ \\
\hline \multicolumn{5}{|l|}{ Risk factors } \\
\hline Cancer & $253(28 \%)$ & 43 (31\%) & $35(22 \%)$ & $175(29 \%)$ \\
\hline Prior VTE & $135(15 \%)$ & $13(9.5 \%)$ & $13(8.3 \%)$ & $109(18 \%)$ \\
\hline \multicolumn{5}{|l|}{ VTE characteristics } \\
\hline Clinically overt PE & $360(40 \%)$ & 67 (49\%) & 77 (49\%) & $216(36 \%)$ \\
\hline \multicolumn{5}{|l|}{ If only DVT signs: } \\
\hline Proximal DVT & 351 (76\%) & 47 (78\%) & 59 (82\%) & $245(75 \%)$ \\
\hline Upper extremity DVT & $65(12 \%)$ & $8(11 \%)$ & $6(7.6 \%)$ & $51(13 \%)$ \\
\hline \multicolumn{5}{|l|}{ Treatment } \\
\hline Initial therapy, UFH & $130(15 \%)$ & $26(19 \%)$ & 24 (15\%) & $80(13 \%)$ \\
\hline Initial therapy, LMWH & 741 (83\%) & $108(79 \%)$ & $131(84 \%)$ & $502(83 \%)$ \\
\hline Mean LMWH doses (IU/kg) & $187 \pm 43$ & $192 \pm 43$ & $186 \pm 44$ & $186 \pm 43$ \\
\hline Long-term, AVK drugs & $566(63 \%)$ & 80 (58\%) & 81 (52\%) & $405(67 \%)$ \\
\hline Long-term, LMWH & $299(33 \%)$ & 52 (38\%) & 69 (44\%) & $178(30 \%)$ \\
\hline Inferior vena cava filter & $35(3.9 \%)$ & $8(5.8 \%)$ & $5(3.2 \%)$ & $22(3.6 \%)$ \\
\hline \multicolumn{5}{|l|}{ 3-month outcome } \\
\hline Major bleeding & $19(2.1 \%)$ & $6(4.4 \%)$ & $6(3.8 \%)$ & $7(1.2 \%)$ \\
\hline Fatal bleeding & $7(0.8 \%)$ & $2(1.5 \%)$ & $3(1.9 \%)$ & $2(0.3 \%)$ \\
\hline Recurrent DVT & $2(0.2 \%)$ & $1(0.7 \%)$ & 0 & $1(0.2 \%)$ \\
\hline Recurrent PE & $10(1.1 \%)$ & $1(0.7 \%)$ & $2(1.3 \%)$ & $7(1.2 \%)$ \\
\hline Fatal PE & $21(2.3 \%)$ & $2(1.5 \%)$ & $12(7.7 \%)$ & 7 (1.2\%) \\
\hline Overall death & 77 (8.6\%) & 13 (9.5\%) & 27 (17\%) & 37 (6.1\%) \\
\hline
\end{tabular}

Abbreviations: VTE, venous thromboembolism; SD, standard deviation; $\mathrm{CrCl}$, creatinine clearance; PE, pulmonary embolism; DVT, deep vein thrombosis; LMWH, low-molecular-weight heparin; AVK, anti-vitamin K drugs; OR, odds ratio; Cl, confidence intervals. 
Table 2 Surgical patients with subsequent VTE and their prophylaxis.

\begin{tabular}{lccccc}
\hline Type of surgery & Patients, N & Mean age (years \pm SD) & Prophylaxis (yes) & Prophylaxis LMWH & Duration (days \pm SD) \\
\hline All & 137 & $60 \pm 20$ & $(\%)$ & $(\%)$ & $30 \pm 58$ \\
Major orthopedic & $24(18 \%)$ & $73 \pm 17$ & $24(100 \%)$ & $22(100 \%)$ & $46 \pm 94$ \\
Other orthopedic & $14(10 \%)$ & $47 \pm 18$ & $12(86 \%)$ & $11(100 \%)$ & $49 \pm 69$ \\
Cancer & $15(11 \%)$ & $69 \pm 11$ & $9(60 \%)$ & $9(100 \%)$ & $17 \pm 10$ \\
Abdominopelvic & $28(20 \%)$ & $54 \pm 20$ & $14(50 \%)$ & $10(83 \%)$ & $19 \pm 11$ \\
Genitourinary & $19(14 \%)$ & $57 \pm 21$ & $10(53 \%)$ & $9(100 \%)$ & $14 \pm 9.2$ \\
Neurosurgery & $9(6.6 \%)$ & $58 \pm 15$ & $2(22 \%)$ & $2(100 \%)$ & $12 \pm 2.8$ \\
Vascular & $5(3.6 \%)$ & $63 \pm 15$ & $10(44 \%)$ & $3(100 \%)$ & $23 \pm 12$ \\
Other & $23(17 \%)$ & $60 \pm 22$ & & $6(67 \%)$ & $18 \pm 9.7$ \\
\hline
\end{tabular}

$60 \pm 20$ years (Table 2). Of these, 49\% initially presented with PE, and only $61 \%$ of them VTE prophylaxis with LMWH was prescribed for $94 \%$ of the patients, frequently for an extended period (i.e., $30 \pm 58$ days). The surgical procedures most frequently involved were orthopedic (18\% had major orthopedic surgery, and $10 \%$ had some other orthopedic procedure), followed by abdominopelvic surgery (20\% for abdominal procedures and $14 \%$ for genitourinary interventions). The rate of VTE after neurosurgery and vascular surgery was relatively low $(6.6 \%$ and $3.6 \%$, respectively). VTE after oncological surgery was reported in $11 \%$ of cases. All other surgical procedures accounted for nearly $17 \%$ of VTE cases.

\section{Immobility and medical illness}

Immobility $\geq \mathbf{4}$ days for nonsurgical procedures was reported in 156 patents (Table 3). Thirty-six percent were male, and their mean age was $74 \pm 16$ years. Of these, $49 \%$ initially presented with PE. Both acute and chronic medical illnesses induced immobility. Among the acute causes of immobility, $5.0 \%$ of patients experienced ischemic events $(1.8 \%$ ischemic heart disease and $3.2 \%$ ischemic stroke), 5.8\% experienced heart failure and $5.1 \%$ experienced acute infection. The chronic medical illness associated with immobility included mainly minor trauma (i.e., injuries that did not require surgery), 17\%; arthropathy, 10\%; COPD, 5.1\%; leg paralysis, $1.3 \%$; cancer, $6.4 \%$; mental disorders, $24 \%$.
VTE prophylaxis was provided for $24 \%$ of immobilized patients, mainly with LMWH, with $32 \pm 47$ days of prophylaxis. Immobilized patients were kept mainly at home (93\% of cases), but a small number of cases stayed in hospitals (3.2\%) or long-term facilities (3.8\%).

\section{Treatment}

Most patients (83\%) received initial therapy with low-molecular-weight heparin (LMWH) or fondaparinux, and 15\% received unfractionated heparin. Less than $2 \%$ underwent thrombolysis or received other drugs as initial therapy. Long-term treatment for VTE was performed with LMWH in $15 \%$ of cases and with AVK drugs in $80 \%$ of cases; in less than $5 \%$ of cases, other drugs were chosen. Vena cava filter placement was performed in $3.9 \%$ of cases.

Of the 137 patients with postoperative VTE, 61\% had received VTE prophylaxis. Of the 156 patients with recent immobility, $24 \%$ had received VTE prophylaxis.

\section{Outcomes}

The incidence of fatal PE during the first 3 months of therapy was $1.5 \%$ for patients with postoperative VTE, $7.7 \%$ for those who had been immobilized, and $1.2 \%$ for patients with unprovoked VTE. The incidence of fatal bleeding was $1.5 \%, 1.9 \%$ and $0.3 \%$, respectively. Of the 137 patients with postoperative

Table 3 Reason for immobility and type of prophylaxis in Italian patients with VTE.

\begin{tabular}{|c|c|c|c|c|c|c|}
\hline Reason for immobility & Patients, N & $\begin{array}{l}\text { Mean age } \\
\text { years } \pm \text { SD) }\end{array}$ & $\begin{array}{c}\text { Place of immobility } \\
\text { (hospital) }\end{array}$ & $\begin{array}{l}\text { Prophylaxis } \\
\text { (yes) }\end{array}$ & $\begin{array}{l}\text { Prophylaxis } \\
\text { with LMWH }\end{array}$ & $\begin{array}{l}\text { Duration } \\
\text { (days } \pm S D \text { ) }\end{array}$ \\
\hline All & 156 & $74 \pm 16$ & $23(15 \%)$ & 38 (24\%) & $22(60 \%)$ & $3.2 \pm 1.1$ \\
\hline Trauma with no surgery & $26(17 \%)$ & $67 \pm 19$ & $2(7.7 \%)$ & $13(50 \%)$ & $11(85 \%)$ & $3.2 \pm 1.0$ \\
\hline Mental disorders & $31(20 \%)$ & $81 \pm 13$ & $2(6.5 \%)$ & $3(9.7 \%)$ & $1(33 \%)$ & $3.6 \pm 1.3$ \\
\hline Acute infection & $8(5.1 \%)$ & $71 \pm 21$ & $2(25 \%)$ & $2(25 \%)$ & $1(50 \%)$ & $2.3 \pm 0.5$ \\
\hline Arthropathy & $16(10 \%)$ & $79 \pm 13$ & $1(6.3 \%)$ & $1(6.3 \%)$ & $0(0 \%)$ & $3.7 \pm 1.1$ \\
\hline Leg paralysis & $2(1.3 \%)$ & $70 \pm 2.8$ & $0(0 \%)$ & $0(0 \%)$ & - & $4.0 \pm 1.4$ \\
\hline Cancer & $10(6.4 \%)$ & $67 \pm 16$ & $1(10 \%)$ & $3(30 \%)$ & $2(67 \%)$ & $2.9 \pm 1.2$ \\
\hline Chronic lung disease & $8(5.1 \%)$ & $76 \pm 6.1$ & $2(25 \%)$ & $1(13 \%)$ & $1(100 \%)$ & $2.9 \pm 1.0$ \\
\hline Acute stroke & $5(3.2 \%)$ & $76 \pm 10$ & $2(40 \%)$ & $1(20 \%)$ & $1(100 \%)$ & $3.2 \pm 1.1$ \\
\hline Heart failure & $9(5.8 \%)$ & $83 \pm 9.0$ & $1(11 \%)$ & $4(44 \%)$ & $1(25 \%)$ & $3.2 \pm 0.8$ \\
\hline Ischemic heart disease & $3(1.9 \%)$ & $72 \pm 2.1$ & $3(100 \%)$ & $3(100 \%)$ & $0(0 \%)$ & $2.7 \pm 0.6$ \\
\hline Other & $38(24 \%)$ & $69 \pm 16$ & 7 (18\%) & 7 (18\%) & $4(67 \%)$ & $3.1 \pm 1.1$ \\
\hline
\end{tabular}


VTE, $61 \%$ had received VTE prophylaxis. Of the 156 patients with recent immobility, $24 \%$ had received VTE prophylaxis.

\section{Discussion}

The data presented in this analysis confirm the existence of significant differences in outcomes (fatal PE, fatal bleeding, and overall death) between surgical patients and immobilized patients treated for acute VTE. Furthermore, a substantial underuse of thromboprophylaxis was found in patients with immobility $\geq 4$ days who eventually developed VTE compared with surgical patients who eventually developed VTE. To our knowledge, this is the first report on the influence of surgery or immobility in Italian patients with VTE. As of July 2008, Italy had enrolled 896 patients in the registry. The literature includes information concerning VTE in Italy from other registries, but their data are different and focused on other topics, as discussed below.

The mean age of the Italian patients enrolled in the RIETE was lower than that reported in the MASTER registry, which also enrolled patients affected by VTE [7]. Moreover, a high incidence of upper limb DVT has been recorded in the RIETE as compared with a previous Italian report by Balbarini et al. [8]. This difference might be related to better surveillance of central venous lines in the upper extremities, especially for oncology patients. One in every three $(61 \%)$ surgical patients with VTE received VTE prophylaxis $(94 \%$ with LMWH). These data are similar to those reported in a previous study by Ricci et al. [9]. However the duration of thromboprophylaxis for surgical patients in the RIETE was more prolonged ( $30 \pm 58$ days), particularly when compared to the data on oncological surgery available from the ARISTOS registry [10].

Different data may be found for nonsurgical immobility. Only one in every 4 medical patients with immobility $>4$ days received VTE prophylaxis (with LMWH in $61 \%$ of patients). This rate of thromboprophylaxis is very low and differs from the data for Italian medical patients reported in another study, although only inpatients were evaluated in that study [11]. Again, in this clinical setting, the duration of thromboprophylaxis was rather long ( $32 \pm 47$ days); however, it may actually be too short given that many medical illnesses (such as end-stage neoplasia, dementia, trauma without surgery, and leg paralysis) often induce prolonged bedrest. In the studied population, prophylaxis was provided for $35 \%$ of inpatients and $41 \%$ of immobilized patients in long-term care centers, but only $19 \%$ of patients treated at home. The evaluation of the duration and discontinuation of thromboprophylaxis in this area should be better evaluated given this patient population's higher risk for recurrences or bleeding complications. The high proportion of patients with dementia (20\%) in our series confirms that many patients were immobilized for long periods. Consequently, prolonged thromboprophylaxis in immobilized patients with chronic medical illness should be considered in further studies, particularly because the current literature does not offer other data from Italy.

The initial therapy of patients with VTE frequently includes the use of unfractioned heparin (15\%), although LMWH use remains considerable (83\%). Other treatments, particularly thrombolysis, are reserved for a reduced number of cases. Long-term VTE treatment with LMWH occurred in an unexpectedly high number of our cases (33\%) compared with the data from WODIT and ISCOAT $[12,13]$, while oral anticoagulation with anti-vitamin $\mathrm{K}$ drugs was used in $63 \%$ of our patients. Other drugs accounted for less than $4 \%$ of patients, and a vena cava filter was inserted in nearly $4 \%$ of patients.

Regarding outcomes after the first three months of follow up, we recorded a $2.1 \%$ incidence of major bleeding events (fatal bleeding: $0.8 \%$ ). These data differ from those reported in ISCOAT [13], although that study recorded a cumulative bleeding incidence for patients receiving ongoing oral anticoagulation for either recent VTE or atrial fibrillation. There was also was a $1.3 \%$ rate of VTE recurrences. This is similar to the rate reported in the PROLONG study, in which a $4.4 \%$ rate of recurrent VTE was reported in patients with increased d-dimer levels after an episode of VTE and the discontinuation of oral anticoagulants [14]. However, these data are different from those reported in the WODIT study and in another study by Prandoni et al. [15]. Finally, $8.6 \%$ of Italian patients died in our series ( $2.3 \%$ from fatal $P E)$; these data are quite similar to those reported in a series by Giuntini et al. [16] and different from those reported by Prandoni et al. [15].

In conclusion, our data from a prospective series of consecutively enrolled patients indicate that immobilized patients with VTE are less likely to receive VTE prophylaxis than surgical patients. Because medical patients with VTE had a worse outcome (mostly due to a more severe presentation of VTE, coexisting underlying conditions, or associated therapies), a higher rate of VTE prophylaxis is warranted. Further studies should focus on this topic, particularly on the prescription of pharmacological prophylaxis and the type and duration of drugs used to reduce the VTE incidence in this clinical area.

$\begin{array}{ll}\begin{array}{l}\text { Coordinator of the } \\ \text { RIETE Registry: }\end{array} & \text { Dr. Manuel Monreal (Spain) } \\ \begin{array}{l}\text { RIETE Steering } \\ \text { Committee }\end{array} & \text { Dr. Hervè Decousus (France) } \\ \text { Members: } & \text { Dr. Paolo Prandoni (Italy) } \\ \text { RIETE National } & \text { Dr. Benjamin Brenner (Israel) } \\ \text { Coordinators: } & \text { Dr. Raquel Barba (Spain) } \\ & \text { Dr. Pierpaolo Di Micco (Italy) } \\ & \text { Dr. Laurent Bertoletti (France) } \\ & \text { Dr. Manolis Papadakis (Greece) } \\ & \text { Dr. Marijan Bosevski (R.Macedonia) } \\ \text { RIETE Registry } & \text { Dr. Henri Bounameaux (Switzerland) } \\ \text { Coordinating } & \text { S \& H Medical Science Service } \\ \text { Center: } & \end{array}$

\section{Conflict of interest statement}

The authors have no conflict of interest.

\section{Acknowledgements}

We express our gratitude to Bayer Schering Pharma for supporting the RIETE registry outside Spain with an unrestricted educational grant. We also thank the Registry Coordinating 
Center, S\& H Medical Science Service, for their quality control, logistic and administrative support, and Prof. Salvador Ortiz, Universidad Autónoma de Madrid and Statistical Advisor of $S \& H$ Medical Science Service, for the statistical analysis of the data presented in this paper.

\section{Appendix A. Italian Members of the RIETE Group}

Barillari A, Barillari G, Ciammaichella M, Di Micco P, Dalla Valle F, Duce R, Maida R, Pasca S, Piovella C, Poggio R, Prandoni P, Quintavalla R, Rota L, Schenone A, Tiraferri E, Tonello D, Visonà A.

\section{References}

[1] Monreal M, Suárez C, Fajardo JA, Barba R, Uresandi F, Valle R, et al., RIETE investigators. Management of patients with acute venous thromboembolism: findings from the RIETE registry. Pathophysiol Haemost Thromb 2003 Sep-2004;33:330-4.

[2] Monreal M, Kakkar AJ, Caprini JA, Barba R, Uresandi F, Valle R, et al., the RIETE INVESTIGATORS. The outcome after treatment of venous thromboembolism is different in surgical and acutelly ill medical patients. Findings from the RIETE Registry. J Thromb Haemost 2004;2:1892-8.

[3] Otero R, Trujillo-Santos J, Cayuela A, Rodríguez C, Barron M, Martín JJ, et al. Haemodinamically unstable pulmonary embolism in the RIETE Registry: systolic blood pressure or shock index? Eur Respir J 2007;30:1111-6.

[4] Laporte S, Mismetti P, Décousus H, Uresandi F, Otero R, Lobo JL, et al., the RIETE investigators. Predictive factors for fatal pulmonary embolism in 15,520 patients with venous thromboembolism. Findings from the RIETE Registry. Circulation 2008;117:1711-6.

[5] Monreal M, Falgá C, Valle R, Barba R, Bosco J, Beato JL, et al., the RIETE Investigators. Venous thromboembolism in patients with renal insufficiency. Findings from the RIETE Registry. Am J Med 2006;119:1073-9.

[6] Lobo JL, Zorrilla V, Aizpuru F, Grau E, Jimenez D, Palareti G, et al. D-dimer levels and 15-day outcome in acute pulmonary embolism. Findings from the RIETE registry. J Thromb Haemost 2009;11:1795-801.

[7] Agnelli G, Verso M, Ageno W, Imberti D, Moia M, Palaretic G, et al., MASTER investigators. The MASTER registry on venous thromboembolism: description of the study cohort. Thromb Res 2008;121:605-10.

[8] Balbarini A, Rugolotto M, Buttitta F, Mariotti R, Strata G, Mariani M. [Deep venous thrombosis: epidemiologic, diagnostic and therapeutic aspects]. Cardiologia 1998;43:605-15.

[9] Ricci A, Laurora G, D'Aulerio A, Mezzanotte A, Belcaro G. [The prevention of venous thromboembolism in Italy]. Minerva Chir 1992;47:1557-61.

[10] Agnelli G, Bolis G, Capussotti L, Scarpa RM, Tonelli F, Bonizzoni E, et al. A clinical outcome-based prospective study on venous thromboembolism after cancer surgery: the @RISTOS project. Ann Surg 2006;243:89-95.

[11] Gussoni G, Campaninin M, Silingardi M, Scannapieco G, Mazzone A, Magni G, et al., GEMINI Study Group. In-hospital symptomatic venous thromboembolism and antithrombotic prophylaxis in Internal Medicine. Findings from a multicenter, prospective study. Thromb Haemost 2009;101:893-901.

[12] Santamaria MG, Agnelli G, Taliani MR, Prandoni P, Moia M, Bazzan M, et al., Warfarin Optimal Duration Italian Trial (WODIT) Investigators. Thrombophilic abnormalities and recurrence of venous thromboembolism in patients treated with standardized anticoagulant treatment. Thromb Res 2005;116: 301-6.

[13] Palareti G, Leali N, Coccheri S, Poggi M, Manotti C, D’Angelo A, et al. Bleeding complications of oral anticoagulant treatment: an inception-cohort, prospective collaborative study (ISCOAT). Italian Study on Complications of Oral Anticoagulant Therapy. Lancet 1996;348:423-8.

[14] Cosmi B, Legnani C, Tosetto A, Pengo V, Ghirarduzzi A, Testa S, et al., PROLONG Investigators (on behalf of Italian Federation of Anticoagulation Clinics). Usefulness of repeated D-dimer testing after stopping anticoagulation for a first episode of unprovoked venous thromboembolism: the PROLONG II prospective study. Blood 2010;115:481-8.

[15] Prandoni P, Lensing AW, Cogo A, Cuppini S, Villalta S, Carta M, et al. The long-term clinical course of acute deep venous thrombosis. Ann Intern Med 1996;125:1-7.

[16] Giuntini C, Di Ricco G, Marini C, Melillo E, Palla A. Pulmonary embolism: epidemiology. Chest 1995 Jan;107(1 Suppl):3S-9S. 